\title{
MONEY IN
}

MONETARY POLICY

DESIGN

MONETARY CROSS-

CHECKING IN THE

NEW-KEYNESIAN

MODEL

by Guenter W. Beck

and Volker Wieland 


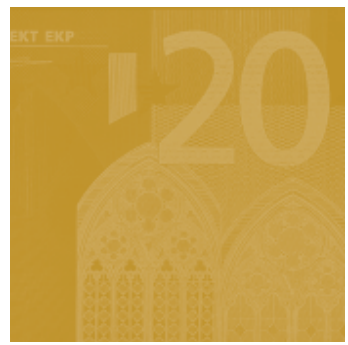

\title{
WORKING PAPER SERIES
}

NO II9I / MAY 20IO

\author{
MONEY IN MONETARY \\ POLICY DESIGN
}

\section{MONETARY CROSS-CHECKING IN THE NEW-KEYNESIAN MODEL'}

by Guenter W. Beck and Volker Wieland ${ }^{2}$

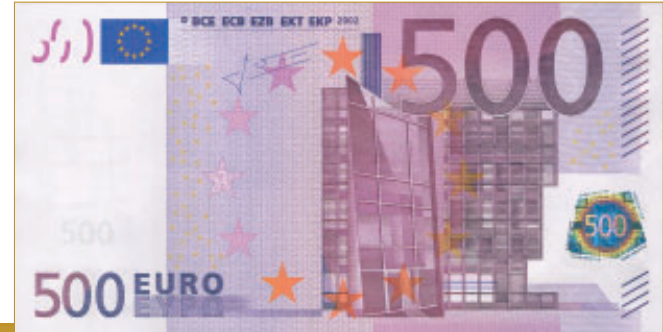

In 2010 all ECB

publications

feature a motif

$€ 500$ banknote.

NOTE: This Working Paper should not be reported as representing the views of the European Central Bank (ECB).

The views expressed are those of the authors and do not necessarily reflect those of the $E C B$.

This paper can be downloaded without charge from http://www.ecb.europa.eu or from the Social Science Research Network electronic library at http://ssrn.com/abstract_id $=|5075| 4$. 
(c) European Central Bank, 2010

\section{Address}

Kaiserstrasse 29

60311 Frankfurt am Main, Germany

\section{Postal address}

Postfach 160319

60066 Frankfurt am Main, Germany

Telephone

+496913440

Internet

http://www.ecb.europa.eu

Fax

+496913446000

All rights reserved.

Any reproduction, publication and reprint in the form of a different publication, whether printed or produced electronically, in whole or in part, is permitted only with the explicit written authorisation of the ECB or the author(s).

Information on all of the papers published in the ECB Working Paper Series can be found on the ECB's website, http://www. ecb.europa.eu/pub/scientific/wps/date/ html/index.en.html

ISSN 1725-2806 (online) 


\section{CONTENTS}

Abstract

Non-technical summary

1 Introduction

2 Optimal monetary policy without money

3 The long-run link between money and inflation and the consequences of persistent central bank misperceptions

4 An interest rate policy with monetary cross-checking

5 Conclusions and outlook

References 


\begin{abstract}
In the New-Keynesian model, optimal interest rate policy under uncertainty is formulated without reference to monetary aggregates as long as certain standard assumptions on the distributions of unobservables are satisfied. The model has been criticized for failing to explain common trends in money growth and inflation, and that therefore money should be used as a cross-check in policy formulation (see Lucas (2007)). We show that the New-Keynesian model can explain such trends if one allows for the possibility of persistent central bank misperceptions. Such misperceptions motivate the search for policies that include additional robustness checks. In earlier work, we proposed an interest rate rule that is near-optimal in normal times but includes a cross-check with monetary information. In case of unusual monetary trends, interest rates are adjusted. In this paper, we show in detail how to derive the appropriate magnitude of the interest rate adjustment following a significant cross-check with monetary information, when the New-Keynesian model is the central bank's preferred model. The cross-check is shown to be effective in offsetting persistent deviations of inflation due to central bank misperceptions.
\end{abstract}

JEL Classification: E32, E41, E43, E52, E58

Keywords: monetary policy, New-Keynesian model, money, quantity theory, European Central Bank, policy under uncertainty. 


\section{Nontechnical summary}

The notion that inflation is a monetary phenomenon is a central tenet of monetary economics. It implies that inflation is ultimately a consequence of monetary policy. This view is usually motivated by the quantity theory. The quantity theory states that sustained increases or decreases in the overall price level occur along with faster or slower growth rates of monetary aggregates adjusted for long-run output and velocity trends. On the basis of this theory, central banks have at times assigned an important role to monetary aggregates in the formulation of monetary policy. A prominent example of such a central bank is the German Bundesbank that had been successful in fighting the inflationary impetus of the 1970s oil price shocks with the help of monetary targets.

Based on the New-Keynesian model which has quickly become the principal workhorse model in monetary economics, recent monetary theory, however, has questioned the usefulness of monetary aggregates for monetary policy. The model suggests that short-term interest rates, the major policy instrument of the central bank, ought to be set with reference to inflation forecasts and output gaps but without direct concern for monetary aggregates. In other words, monetary information is of no particular use for the conduct of monetary policy in these models.

Moreover, the importance of monetary aggregates has also declined in central bank practice as, e.g., the case of the U.S. Fed shows which already de-emphasized the role of monetary aggregates in its strategy in the early 1990s.

Nevertheless, some central banks and some monetary theorists still hold out for a special role for money in the formulation of monetary policy. The European Central Bank did not adopt the Bundesbank's monetary targets but it maintains that its monetary analysis is important enough to deserve to particular consideration separately from its other economic analysis. Intellectual support for the inclusion of a separate monetary pillar in the ECBs strategy is provided, e.g., by Lucas (2007) who emphasizes with reference to the inability of the standard New-Keynesian model to satisfactorily explain long-run trends in money and inflation that "monetary information should continue be used as a kind of add-on or cross-check, just as it is in the ECB policy formulation today."

In this paper, we review the implications of the New-Keynesian model for the role of monetary aggregates and aim to address the criticisms raised by Lucas (2007). We elaborate on earlier work in Beck and Wieland (2008) with a more thorough and detailed exposition of our analysis in the New-Keynesian model. First, we reiterate the case for monetary policy without money. We note that it also applies under conditions of uncertainty as long as certain standard assumptions on the distributions of unobservable variables and error terms are satisfied. When we extend the New-Keynesian model to allow for persistent central bank misperceptions regarding unobservables such 
as (flexible-price) equilibrium output or equilibrium interest rates we are able to give a unified account of trends in inflation and monetary aggregates. Furthermore, we find that adding a cross-check regarding filtered money growth to the optimal interest-rate policy under perfect information provides superior inflation control in the presence of persistent central bank misperceptions. Specifically, we utilize the formulation of monetary crosschecking suggested by Beck and Wieland (2007) as a potential formal characterization of the ECBs two-pillar strategy. Here, we discuss in detail how to derive the appropriate magnitude of the interest rate adjustment following a significant cross-check with monetary information in the New-Keynesian model. This cross-check is shown to be effective in offsetting persistent deviations of inflation in response to central bank misperceptions. 


\section{Introduction}

The notion that inflation is a monetary phenomenon is a central tenet of monetary economics. It implies that inflation is ultimately a consequence of monetary policy, and the same conclusion is applied to deflation. This view is usually motivated by the quantity theory. The quantity theory states that sustained increases or decreases in the overall price level occur along with faster or slower growth rates of monetary aggregates adjusted for long-run output and velocity trends. On the basis of this theory, central banks have at times assigned an important role to monetary aggregates in the formulation of monetary policy. For example, the U.S. Federal Reserve emphasized the role of monetary aggregates when Chairman Paul Volcker set out to overcome the great inflation in the United States in 1979. Perhaps, he was partly following the earlier example of the German Bundesbank that had been more successful in fighting the inflationary impetus of the 1970s oil price shocks with the help of monetary targets.

Recent monetary theory, however, has questioned the usefulness of monetary aggregates for monetary policy. For example, Woodford (2006) asks "How important is money in the conduct of monetary policy?" 1 and responds:

"I believe that a serious examination of the reasons given thus far for assigning a prominent role to monetary aggregates in (policy) deliberations provides little support for a continued emphasis on those aggregates."

With regard to further efforts aimed at achieving a better understanding of the dynamics of monetary aggregates Michael Woodford concludes:

“.. There is at present little reason ... to devote much attention to questions such as the construction of improved measures of the money supply or improved econometric models of money demand. For there is little intelligible connection between those questions and the kinds of uncertainty about the effects of monetary policy that are the actual obstacles to the development of more effective, more reliable and more transparent ways of conducting policy."

These conclusions are based on the New-Keynesian model of monetary policy. This model as laid out by Rotemberg and Woodford (1997) and Goodfriend and King (1997) and developed in detail in Woodford (2003) has quickly become the principal workhorse model in monetary economics. Requiring only a small number of equations and variables the model has proved very useful in deriving several important principles for the conduct of monetary policy (see for example, Kerr and King (1996) and Clarida et al.

\footnotetext{
${ }^{1}$ This question formed the title of his contribution to the Fourth ECB Central Banking Conference "The Role of Money: Money and Monetary Policy in the Twenty-First Century", November 9-10, 2006.
} 
(1999)). It suggests that optimal interest rate policy ought to be conducted with reference to inflation forecasts and output gaps but without direct concern for monetary aggregates.

The importance of monetary aggregates has also declined in central bank practice. For example, the U.S. Fed already de-emphasized the role of monetary aggregates in its strategy in the early 1990s, but perhaps more because of empirical difficulties than because of new theories. Also, nowadays no central bank pursues a strategy of monetary targeting. The Bundesbank's difficulties with meeting short-term monetary growth targets also became very apparent in the 1990s.

Nevertheless, some central banks and some monetary theorists still hold out for a special role for money in the formulation of monetary policy. The European Central Bank did not adopt the Bundesbank's monetary targets but it maintains that its monetary analysis is important enough to deserve to particular consideration separately from its other economic analysis. Otmar Issing, the ECB's former chief economist, describes the separate monetary pillar in the ECB strategy as follows:

"In line with the argument of a closer relationship between money and inflation at lower frequencies, the function ascribed to the monetary pillar is to reveal medium-term risks to price stability ..” but "... there is no mechanical monetary policy reaction to deviations of M3 growth from the reference value" and "... cross-checking the information from the economic analysis with the information from the monetary pillar is ... a crucial element underpinning the robustness and medium-term policy orientation."

In a recent contribution Lucas (2007) comments on the conflict between the ECB's strategy and the findings of New Keynesian monetary theory with the following words:

“Events since 1999 have not tested the importance of the (ECB's) second, monetary pillar, ... I am concerned that this encouraging but brief period of success will foster the opinion, already widely held, that the monetary pillar is superfluous, and lead monetary policy analysis back to the kind of muddled eclecticism that brought us the 1970s inflation."

Robert Lucas identifies New-Keynesian-style research as one of the possible culprits stating

"One source of this concern is the increasing reliance of central bank research on New-Keynesian modeling. New-Keynesian models define monetary policy in terms of a choice of money market rate and so make direct contact with central banking practice. Money supply measures play no role in the estimation, testing or policy simulation of these models. A role for 
money in the long run is sometimes verbally acknowledged, but the models themselves are formulated in terms of deviations from trends that are themselves determined somewhere off stage."

He then goes on to propose the following strategies for research and policy making:

"It seems likely that these models could be reformulated to give a unified account of trends, including trends in monetary aggregates, and deviations about trend but so far they have not been. This remains an unresolved issue on the frontier of macroeconomic theory. Until it is resolved, monetary information should continue be used as a kind of add-on or cross-check, just as it is in the ECB policy formulation today."

In this paper we review the implications of the New-Keynesian model for the role of monetary aggregates and aim to address the criticisms raised by Lucas (2007). We elaborate on earlier work in Beck and Wieland (2008) with a more thorough and detailed exposition of our analysis in the New-Keynesian model. First, we reiterate the case for monetary policy without money. We note that it also applies under conditions of uncertainty as long as certain standard assumptions on the distributions of unobservable variables and error terms are satisfied. Then, we introduce persistent central bank misperceptions regarding unobservables such as potential output or equilibrium interest rates. Such misperceptions lead to persistent policy errors and sustained trends in money growth and inflation. In this manner, we are able to provide a unified account of trends in inflation and monetary aggregates as requested by Lucas (2007).

Beck and Wieland $(2007 \mathrm{a}, \mathrm{b})$ proposed an interest rate rule that captures the idea of an add-on or cross-check with monetary information in a formal manner. ${ }^{2}$ Here, we discuss in detail how to derive the appropriate magnitude of the interest rate adjustment following a significant cross-check with monetary information in the New-Keynesian model. This cross-check is shown to be effective in offsetting persistent deviations of inflation in response to central bank misperceptions.

\section{Optimal monetary policy without money}

In the New-Keynesian model monetary aggregates play no direct role in the transmission of monetary policy to output and inflation. Monetary policy decisions are made with regard to the nominal interest rate. A change in the nominal rate affects the real interest rate because not all prices adjust flexibly and immediately. The presence of such price

\footnotetext{
${ }^{2}$ Our characterization of monetary cross-checking differs from Christiano and Rostagno (2001) who propose an escape clause for Taylor rules that helps exclude the possibility of multiple equilibria and selffulfilling expectations. This escape clause involves a commitment to monetary targeting if money growth gets of bounds. If effective it never needs to be implemented.
} 
rigidities introduces real effects of monetary policy. The real interest rate influences aggregate demand. Thus, a change in the real rate can increase or diminish the gap between actual output and the economy's potential that would be realized if the price level would be adjusting flexibly. Changes in the output gap in turn impact on inflation via the New-Keynesian Phillips curve.

Of course, the supply of money is influenced by the open-market operations that the central bank conducts in order to achieve the intended rate of interest. Actual money growth then results from the interplay of money supply and money demand in a recursive manner. The central bank supplies sufficient money to satisfy demand for real balances at the intended rate of interest, the current price level and current income. Consequently, the optimal interest rate policy may be characterized without any recourse to monetary aggregates. From this perspective, efforts to construct better measures of the money supply or to obtain better empirical estimates of the parameters governing money demand are not likely to help improve the performance of monetary policy.

In the following, we present this implication of the New-Keynesian analysis of monetary policy in the context of a simple linearized version of the benchmark model of Rotemberg and Woodford (1997) and Goodfriend and King (1997). This model has been used to study a variety of implications for monetary policy design. A widely-cited example is Clarida et al. (1999). For a detailed exposition of the model and a derivation of the linear approximation the reader is referred to the influential monograph of Woodford (2003).

\section{The model}

In its simplest form the model consists of two key equations, a forward-looking Phillips curve derived from the firms' pricing problem under monopolistic competition and Calvo-style price rigidity, and an aggregate demand relation, the forward-looking IS curve, that is derived from the households' intertemporal Euler equation. As in Clarida et al. (1999) a money-demand relation may be added as a third behavioral equation in the model.

The linearized Phillips curve relation determines the deviation of inflation, denoted by $\pi_{t}$, from its steady-state, $\bar{\pi}$, as a function of expected future inflation, the output gap and cost-push shocks:

$$
\pi_{t}-\bar{\pi}=\lambda\left(y_{t}-z_{t}\right)+\beta\left(\pi_{t+1 \mid t}^{e}-\bar{\pi}\right)+u_{t}, \text { where } \pi_{t+1 \mid t}^{e}=E_{t}\left[\pi_{t+1}\right] .
$$

Expectations regarding future inflation are formed in a rational, forward-looking manner. The output gap is measured as the difference between actual output, $y_{t}$, and the level of output that would be realized if prices were completely flexible, $z_{t}$. In the NewKeynesian world this is the appropriate measure of potential or natural output to appear 
in the Phillips curve relation. The parameter $\lambda$ is a decreasing function of the discount factor $\beta$ and the share of firms that do not adjust their prices in any given period. ${ }^{3}$ The third determinant of inflation in the model, the cost-push shock, is denoted by $u_{t}$.

The linearized version of the New-Keynesian IS curve then relates actual output, $y_{t}$, defined as percentage deviation from steady state, to expected future output, the expected real interest rate and a demand shock:

$$
y_{t}=y_{t+1 \mid t}^{e}-\varphi\left(i_{t}-\pi_{t+1 \mid t}^{e}\right)+g_{t} .
$$

The real interest rate is defined as the difference between the short-term nominal interest rate, $i_{t}$, that is under the control of the central bank and expected inflation. The demand or preference shock is denoted by $g_{t}$. Clarida et al. (1999) assume that the cost-push and demand shocks are observable at time $t$ and follow AR(1) processes, i.e.

$$
\begin{gathered}
u_{t}=\rho_{u} u_{t-1}+\eta_{t}^{u}, \\
g_{t}=\rho_{g} g_{t-1}+\eta_{t}^{g}
\end{gathered}
$$

with $0 \leq \rho_{u}, \rho_{g}<1$ and $\left(\eta_{t}^{g}, \eta_{t}^{u}\right)$ representing mean-zero, i.i.d. disturbances. The unrealistic observability assumption will be abandoned further on in this paper.

We also follow Clarida et al. (1999) in modeling money demand. Demand for real balances is influenced by the demand for transactions as measured by aggregate income, the opportunity cost as measured by the nominal money market rate and other factors captured by shocks. The respective money demand equation is given by:

$$
m_{t}-p_{t}=\gamma_{y} y_{t}-\gamma_{i} i_{t}+s_{t}
$$

Here, $m_{t}$ refers to the logarithm of nominal money balances and $p_{t}$ to the (log of) the price level. Thus, $\Delta p_{t}=\pi_{t} \cdot \gamma_{y}$ denotes the income elasticity and $\gamma_{i}$ the semi-interest rate elasticity of money demand. Money demand shocks, $s_{t}$, are normally distributed with mean zero and variance $\sigma_{s}^{2}$. It is possible to derive this specification of money demand from first principles. As shown in Woodford (2003) it requires that utility is separable in consumption and real money balances. Theoretical foundations for a direct role of real money balances in the IS and Phillips curves can be obtained when household utility is not separable in money and consumption. Empirical studies, however, have failed to detect strong direct effects (cf. Ireland (2004) and Andres et al. (2006)) of real balances. Thus, we will exclude this possibility in the remainder of the paper, while exploring other roles for money in monetary policy design.

\footnotetext{
${ }^{3}$ More precisely, the parameter $\lambda$ is given by the following expression: $\lambda=(1-\theta)(1-\beta \theta)(\theta)^{-1}$, where $\theta$ denotes the proportion of firms that are not allowed to adjust their prices in a given period.
} 


\section{Optimal interest rate policy}

The optimal interest rate policy is determined from the perspective of the central bank's chosen objective. For simplicity, we focus on the objective of a central bank that strictly concentrates on stabilizing actual inflation, $\pi_{t}$, close to its target denoted by $\pi^{*}$,

$$
\max -\frac{1}{2} E_{t}\left\{\sum_{i=0}^{\infty} \beta^{i}\left[\left(\pi_{t+i}-\pi^{*}\right)^{2}\right]\right\},
$$

subject to the Phillips curve and the IS curve defined by equations (1) and (2). The inflation target is normalized at zero, $\pi^{*}=0$. The term "strict inflation targeting" used to describe this strategy was coined by Svensson (1997). It implies that the central bank focuses exclusively on stabilizing inflation without assigning any weight to economic activity in the policy objective.

The associated first-order condition is

$$
E\left[\pi_{t+i} \mid t\right]=\pi^{*}=0 \quad \forall i=\{0,1,2, . ., \infty\}
$$

where $\pi_{t+i}$ depends on the output gap, $y_{t+i}-z_{t+i}$, according to the New-Keynesian Phillips curve. We assume that information is symmetric. The central bank and market participants share the same information. It follows that the central bank and market participants expect future inflation to be equal to the target rate of zero:

$$
\pi_{t+1 \mid t}^{e}=0
$$

Normally, it would be important to discuss at this point whether the central bank is able credibly commit to a policy rule, or whether policy is to be analyzed under the assumption of discretion. However, in the case of a strict-inflation-targeting central bank the optimal policies under commitment and under discretion are identical and follow from the preceding first-order condition.

Solving the Phillips curve for $y_{t}$ and applying $\pi_{t+1 \mid t}^{e}=0$ yields the level of output that would be compatible with the expected rate of inflation in period $t:{ }^{4}$

$$
y_{t}=z_{t}-\frac{1}{\lambda} u_{t}
$$

Similarly, the level of output in period $t+1$ that would be consistent with optimal policy under current information is given by:

$$
y_{t+1 \mid t}^{e}=z_{t+1 \mid t}^{e}-\frac{\rho_{u}}{\lambda} u_{t}
$$

The appropriate level of the nominal interest rate that achieves the central bank's objec-

\footnotetext{
${ }^{4}$ Here, steady-state inflation $\bar{\pi}$ is normalized at zero consistent with the inflation target.
} 
tive can then be derived from equation (2), the New-Keynesian IS curve, evaluated at the intended levels of output and inflation for periods $t$ and $t+1$ :

$$
z_{t}-\frac{1}{\lambda} u_{t}=z_{t+1}^{e}-\frac{\rho_{u}}{\lambda} u_{t}-\varphi\left(i_{t}-0\right)+g_{t}
$$

Thus, the optimal interest rate, $i_{t}$, is:

$$
i_{t}=\frac{1}{\varphi}\left(z_{t+1 \mid t}^{e}-z_{t}+\frac{1-\rho_{u}}{\lambda} u_{t}+g_{t}\right) .
$$

This characterization of optimal interest rate policy has several interesting implications regarding the role of money in monetary policy design. As previously stated the monetary aggregate, $m_{t}$, plays no role in the characterization of optimal interest rate policy. Therefore, improvements in the measurement of monetary aggregates are not likely to improve policy design. Furthermore, the money demand relation, equation (5), is not used in the derivation of the optimal interest rate policy. Thus, money demand parameters do not appear in the optimal policy. Rather, the parameters of the Phillips curve and IS curve turn out to be of importance. This result reinforces the conclusion that research efforts be better spent on obtaining better estimates of the slope of the Phillips curve or the interest-rate elasticity of aggregate demand than estimates of the incomeand interest-rate elasticities of money demand.

To be clear, the central bank achieves the desired interest rate setting by conducting open-market operations that influence the money supply. Thus, the money supply is determined according to the money demand equation (5) consistently with the desired policy rate, current output and the price level. However, money does not appear as a variable in the central bank's optimal interest rate rule and the remainder of the economy is automatically insulated from money demand shocks. Thus, the case for monetary policy design without money directly follows from the New-Keynesian model.

One difference between the optimal interest rate policy given by equation (12) and the characterizations reported by Clarida et al. (1999) and Rotemberg and Woodford (1997) is the presence of current and expected future potential output, $z_{t}$ and $z_{t+1}$. This apparent difference is easily reconciled. For example, if potential output equals steadystate output one obtains the optimal policy from Clarida et al. (1999):

$$
i_{t}=\frac{1-\rho_{u}}{\varphi \lambda} u_{t}+\frac{1}{\varphi} g_{t}
$$

It implies that the central bank acts to fully offset the effects of both demand and costpush shocks on inflation under a strict-inflation targeting regime. In Rotemberg and Woodford (1997) potential output may deviate from steady-state output in response to particular shocks. For example, they incorporate government spending and include a government spending shock in place of the demand or preference shock in Clarida et al. 
(1999). As a result, potential or flexible-price output partly moves with the government spending shock. Furthermore, changes in productivity such as technology shocks are typically assumed to be important drivers of potential output.

A crucial weakness of the above characterization of optimal interest rate policy is that it is not implementable in practice. Neither current potential output, nor future potential output, nor cost-push shocks, nor demand shocks, nor technology shocks are directly observable. All these variables are unknowns that need to be estimated conditional on a particular model of the economy.

This weakness can be addressed by relaxing the assumption of full information on behalf of the central bank and market participants. In doing so we will continue to treat the central bank and market participants symmetrically. In other words, we will continue to assume that they share the same beliefs regarding the appropriate model of the economy.

\section{Introducing imperfect knowledge}

In the following, we introduce imperfect knowledge regarding economic shocks and unobservable variables such as potential output into the analysis. The superscript ${ }^{e}$ is used to refer to the central bank's and public's estimates or perceptions. Thus, $z_{t \mid t}^{e}$ denotes the central bank's estimate of potential output in period $t$ given the information available at that point in time. Similarly, $u_{t \mid t}^{e}, g_{t \mid t}^{e}$ and $s_{t \mid t}^{e}$ refer to the central bank's estimates of these particular economic shocks. We assume that these perceptions represent the best available estimates of the unobservables from the perspective of the central bank. These estimates form the basis for the central bank's forecast of period $t$ inflation, $\pi_{t \mid t}^{e}=E\left[\pi_{t} \mid t\right]$, at the point in period $t$ when it decides on its policy before it can observe the joint consequences of potential output, the cost-push shock and its policy choice on inflation.

Fortunately, the optimal policy under uncertainty can be determined quite easily if the following conditions are fulfilled: the model is linear, the parameters are treated as known and uncertainty is additive. In this case, certainty-equivalence applies. Or in other words, the optimal policy must continue to satisfy the same first-order condition as before, equation (7), with the expectation conditional on the above estimates (see for example Svensson and Woodford (2003) and Wieland (2006)). ${ }^{5}$ Thus, the optimal output level in period $t$ is determined similarly to equation (9) but now in expected terms based on the best available estimates of the cost-push shock and current potential output:

$$
y_{t \mid t}^{e}=z_{t \mid t}^{e}-\frac{1}{\lambda} u_{t \mid t}^{e}
$$

The conditions for certainty-equivalence — linearity, known parameters and additive

\footnotetext{
${ }^{5}$ Certainty-equivalence fails if multiplicative parameters such as $\lambda$ are unknown. Then, the central bank faces a complex control and estimation problem. Examples are studied by Wieland (2000), Beck and Wieland (2002) and Wieland (2006).
} 
uncertainty — require making important a-priori assumptions regarding the processes that determine unobservable variables. Svensson and Woodford (2003), for example, assume that potential output, $z_{t}$, in the New-Keynesian model follows an auto-regressive process,

$$
z_{t}=\rho_{z} z_{t-1}+\varepsilon_{t}^{z}
$$

with known persistence parameter, $\rho_{z}$, and known variance, $\sigma_{\varepsilon_{z}}$. This strategy is often employed in studies of optimal policy under uncertainty. Another example is Wieland (2006) who makes a similar assumption regarding the natural rate of unemployment in a model of the Phillips curve with backward- and forward-looking elements.

With regard to the cost-push shock as well as the demand and money-demand shocks, we use another commonly employed assumption. Central bank and market participants only obtain noisy signals denoted by $u_{t}^{e}, g_{t}^{e}$ and $s_{t}^{e}$. Thus, the true shocks are related to these signals according to

$$
\begin{aligned}
& u_{t}=u_{t}^{e}+\varepsilon_{t}^{u} \\
& g_{t}=g_{t}^{e}+\varepsilon_{t}^{g} \\
& s_{t}=s_{t}^{e}+\varepsilon_{t}^{s}
\end{aligned}
$$

where $\varepsilon_{t}^{u}, \varepsilon_{t}^{g}$, and $\varepsilon_{t}^{s}$ are Gaussian white noise processes with zero mean and known variances, $\sigma_{\varepsilon}^{u}, \sigma_{\varepsilon}^{g}$, and $\sigma_{\varepsilon}^{s}$. Consequently the best estimates of the shocks correspond to $u_{t \mid t}^{e}=u_{t}^{e}, g_{t \mid t}^{e}=g_{t}^{e}$ and $s_{t \mid t}^{e}=s_{t}^{e}$.

Given the above-mentioned assumptions the central bank can solve the estimation problem separately from the optimal policy problem. Svensson and Woodford (2003) and Wieland (2006) show how to derive the optimal estimate of potential output, $z_{t \mid t}^{e}$, using the Kalman filter. Conditional on this estimate the optimal policy implies setting the nominal interest rate, $i_{t}$, so as to achieve the output level defined by (14) in expectation. The appropriate interest rate may be inferred from the IS equation (11). Thus, the optimal policy under imperfect knowledge corresponds to:

$$
i_{t}=\frac{1}{\varphi}\left(z_{t+1 \mid t}^{e}-z_{t \mid t}^{e}+\frac{1-\rho_{u}}{\lambda} u_{t}^{e}+g_{t}^{e}\right)
$$

Introducing imperfect knowledge per se does not change our earlier conclusions. Optimal interest rate policy is defined without any reference to monetary aggregates. Improved information on money does not help improve the performance of interest rate policy.

As noted previously, the optimal policy depends importantly on the central bank's estimate of potential output, $z_{t \mid t}$. A possible route for further investigation would be to follow Svensson and Woodford (2003) and Wieland (2006) and study the performance of policy conditional on an a-priori assumption concerning the unobservable process of 
potential output such as equation (15). Clearly, findings obtained in this manner would only be reliable if potential output truly obeys such a process.

Instead, we pursue a different strategy in our further analysis. This strategy follows the influential study of Orphanides (2003). It implies evaluating policy performance for particular scenarios with persistent deviations of the central bank's estimates of potential output from the true values. Orphanides et al. (2000) and Orphanides (2003) showed that historical output gap estimates have been revised repeatedly. The revisions were due to changing views on the appropriate estimate of potential output. Relative to the final estimate of potential output obtained many years later, the Federal Reserve's real-time estimates indicate highly persistent misperceptions. ${ }^{6}$ Similar misperceptions occurred in other countries. Gerberding et al. (2006), for example, provide data on German output gap misperceptions. If a central bank relies on such potential output measures in real time policy making, its policy stance may be biased for a sustained period of time.

Thus, we consider the possibility that the central bank and the public may make persistent mistakes in estimating the natural output level - even if they obtain those estimates using all available information conditional on their preferred model and estimation method. The estimate, $z_{t \mid t}^{e}$, differs from the true level, $z_{t}$, to the extent of the misperception, $e_{t}$ :

$$
z_{t \mid t}^{e}=z_{t}+e_{t}
$$

The misperception, $e_{t}$, affects the final outcomes for aggregate output, money growth and inflation via central bank policy and market participants' expectations. The resulting level of output is given by:

$$
\begin{aligned}
y_{t} & =y_{t+1 \mid t}^{e}-\varphi\left(i_{t}-\pi_{t+1 \mid t}^{e}\right)+g_{t} \\
& =z_{t+1 \mid t}^{e}-\frac{\rho_{u}}{\lambda} u_{t}^{e}-\varphi\left(\frac{1}{\varphi}\left(z_{t+1 \mid t}^{e}-z_{t \mid t}^{e}+\frac{1-\rho_{u}}{\lambda} u_{t}^{e}+g_{t}^{e}\right)-0\right)+g_{t} \\
& =z_{t}+e_{t}-\frac{1}{\lambda} u_{t}^{e}+\varepsilon_{t}^{g} .
\end{aligned}
$$

If the central bank overestimates potential output by $e_{t}$, its policy will increase the output gap, $y_{t}-z_{t}$, by the same amount $e_{t}$. As a result, inflation will increase by $\lambda e_{t}$ over and

\footnotetext{
${ }^{6}$ The output gap data for the 1980s and 1990s of Orphanides (2003) was constructed from the Greenbook, the Federal Reserve document summarizing the Board staff's analysis of economic developments distributed to the FOMC members a few days before each FOMC meeting. For the 1960s and 1970s Orphanides could not recover a complete time series for potential output estimates from Federal Reserve sources but notes that discussion of output gap measures appeared in the FOMC Memorandum of Discussion throughout this period. Thus, he uses real-time estimates of potential output that were produced by the Council of Economic Advisers (CEA) in those years and available at FOMC meetings. Orphanides et al. (2000) estimate a worst-case process of misperceptions with a near unit-root (0.96) and standard deviation of $3.77 \%$ using quarterly revisions from 1966 to 1994.
} 
above the unavoidable fluctuations due to the noise terms $\varepsilon_{t}^{g}$ and $\varepsilon_{t}^{u}$ :

$$
\begin{aligned}
\pi_{t} & =\lambda\left(y_{t}-z_{t}\right)+\beta \pi_{t+1 \mid t}^{e}+u_{t} \\
& =\lambda\left(z_{t}+e_{t}-\frac{1}{\lambda} u_{t}^{e}+\varepsilon_{t}^{g}-z_{t}\right)+\beta * 0+u_{t} \\
& =\lambda e_{t}+\lambda \varepsilon_{t}^{g}+\varepsilon_{t}^{u}
\end{aligned}
$$

Inflation consequently inherits the persistence properties of the central bank misperceptions. Trend increases or decreases in inflation may therefore be caused by such misperceptions. This point has been made by Orphanides (2003) for the case of a traditional Keynesian-style model with backward-looking expectations formation. In the present paper and in Beck and Wieland (2008) it is extended to the New-Keynesian model with rational expectations. The next step is to address the request of Lucas (2007) and investigate whether the New-Keynesian model with persistent misperceptions may give a unified account of trends, including trends in monetary aggregates.

\section{The long-run link between money and inflation and the con- sequences of persistent central bank misperceptions}

Researchers and policymakers that are in favor of assigning a special role to money in monetary policy design typically emphasize the long-run link between money and inflation, or in other words, the quantity theory. This long-run relation is consistent with the New-Keynesian model discussed in the preceding section. Taking first differences and re-arranging the money demand equation (5) we obtain a short-run link between money and inflation:

$$
\pi_{t}=\Delta p_{t}=\Delta m_{t}-\gamma_{y} \Delta y_{t}+\gamma_{i} \Delta i_{t}-\Delta s_{t} .
$$

$\Delta$ is the first-difference operator. Long-run equilibrium values can then be determined as follows. In the long-run, money demand shocks would average to zero, and the nominal interest rate would settle down to its steady state level, which is the sum of the equilibrium real interest rate and the inflation target. Thus, the change in the interest rate would similarly converge to zero. The long-run link between inflation, money growth and output growth then corresponds to:

$$
\bar{\pi}=\Delta \bar{m}-\gamma_{y} \Delta \bar{y}=\bar{\mu} .
$$


This relationship also incorporates the long-run trend in velocity. Thus, long-run inflation is proportional to long-run money growth adjusted for output and velocity trends. ${ }^{7}$

Recent studies obtained empirical support for this long-run relationship by comparing money and inflation trends estimated with different filtering methods. ${ }^{8}$ Even more interestingly, they claim that money growth leads inflation at low frequencies. To give an example, Gerlach (2004) uses the following filter

$$
\mu_{t}^{f}=\mu_{t-1}^{f}+\omega\left(\mu_{t}-\mu_{t-1}^{f}\right)
$$

to approximate long-run values of inflation and money growth. In his work, $\mu_{t}$, may alternatively stand for money growth, $\Delta m_{t}$, or money growth adjusted for output growth. In this paper we adjust money growth as indicated by equation (24) using the estimate of the income-elasticity of money demand, i.e.

$$
\mu_{t}^{f}=\Delta m_{t}^{f}-\gamma_{y} \Delta y_{t}^{f} .
$$

In order to show that introducing persistent central bank misperceptions into the New-Keynesian model is sufficient to generate similar trend movements in money and inflation - the challenge posed by Lucas - we calibrate and simulate the model under imperfect knowledge. The calibrated parameter values are summarized in Table 1. The economic parameters $\left(\beta, \varphi, \lambda, \gamma_{y}, \gamma_{i}\right)$ are set at values consistent with other studies in the New-Keynesian literature. The variances of the economic shocks are all set to 0.8 . The variance of the noise terms is smaller with regard to money than with regard to output and inflation, because monetary data is available earlier at monthly frequency and subject to less revision (see Coenen et al. (2005)). The persistence of the economic shocks, $\left(\rho_{u}, \rho_{g}\right)$, is set to zero. The filtering parameter, $\omega$, is set in line with values investigated by Gerlach (2004).

To illustrate the effect of sustained misperceptions we construct a simple example. This particular series of output gap misperceptions measured in percentage point terms was also previously used in Beck and Wieland (2007a) in the context of a model with

\footnotetext{
${ }^{7}$ Specifically, with velocity defined as $v_{t} \equiv-m_{t}+p_{t}+y_{t}$ and money demand determined by equation (5) the long-run trend in velocity corresponds to $\Delta \bar{v}=\left(1-\gamma_{y}\right) \Delta \bar{y}$. Changes in the trend in velocity may arise from changes in potential output growth $\bar{y}$, changes in the income elasticity of money demand, $\gamma_{y}$, and possibly from other sources such as financial innovations (see Orphanides and Porter (2001) and Masuch et al. (2001)).

${ }^{8}$ See for example Gerlach (2004), Benati (2005), Pill and Rautananen (2006) and Assemacher-Wesche and Gerlach (2007).
} 
Table 1: Calibration

\begin{tabular}{|c|c|c|}
\hline Parameter & Value & Economic interpretation \\
\hline$\beta$ & 0.99 & Discount factor of the policy maker. \\
\hline$-\varphi$ & -1 & $\begin{array}{l}\text { Real interest rate elasticity of aggregate demand (in line } \\
\text { with Andres et al. (2006) and Ireland (2004)). }\end{array}$ \\
\hline$\theta$ & 0.5 & $\begin{array}{l}\text { Proportion of firms that adjust prices in a given period } \\
\text { (based on Bils and Klenow (2004)). As a result } \lambda=0.5 \\
\text { (rounded). }\end{array}$ \\
\hline$\gamma_{y}$ & 0.1 & $\begin{array}{l}\text { Income elasticity of money demand (in line with } \\
\text { Andres et al. (2006) and Ireland (2004)). }\end{array}$ \\
\hline$-\gamma_{i}$ & -0.4 & $\begin{array}{l}\text { Interest rate elasticity of money demand (in line with } \\
\text { Andres et al. (2006) and Ireland (2004)). }\end{array}$ \\
\hline$\omega$ & 0.2 & $\begin{array}{l}\text { Weighting parameter of filter (broadly in line with } \\
\text { Gerlach (2004)). }\end{array}$ \\
\hline$\pi^{\star}$ & 0 & Inflation target. \\
\hline$\rho_{u}, \rho_{g}$ & 0 & Persistence of cost-push and aggregate demand shocks. \\
\hline$\sigma_{\eta}^{g}, \sigma_{\eta}^{u}, \sigma_{\eta}^{s}$ & 0.8 & $\begin{array}{l}\text { Standard deviation of cost-push, demand and money- } \\
\text { demand shocks. }\end{array}$ \\
\hline$\sigma_{\varepsilon}^{u}$ & 0.6 & Standard deviation of noise of cost-push shocks. \\
\hline$\sigma_{\varepsilon}^{g}$ & 0.4 & Standard deviation of noise of demand shock. \\
\hline$\sigma_{\varepsilon}^{s}$ & 0.1 & Standard deviation of noise of money-demand shocks. \\
\hline
\end{tabular}

backward-looking expectations formation.

$$
\begin{array}{ll}
\text { for } t=(1,10) & e(t)=0 \\
\text { for } t=(11,12,13,14) & e(t)=(1,2,3,4) \\
\text { for } t=(15,100) & e(t)=4 \\
\text { for } t=(101,102,103) & e(t)=(3,2,1) \\
\text { for } t=(104,200) & e(t)=1 .
\end{array}
$$

The central bank's initial estimate of potential output is assumed to coincide with the true value. In periods 11 to 14 the central bank overestimates potential output growth by 1 percentage point per period. As a consequence, the central bank's and the public's estimate of the output gap is 4 percentage points lower than the true output gap from period 15 onwards. As a result of this mistake the central bank will induce a level of output that is 4 percentage points above potential on average. Ultimately, this policy bias induces an increase in average inflation of about 2 percentage points. This value corresponds to $\left(\lambda e_{t}\right)$. Accordingly, average money growth will also tend to rise by 2 percentage points. From period 100 onwards the central bank's overestimate of potential output declines to 1 percentage point and the resulting deviation in average inflation to 0.5 percentage points.

A simulation of the consequences of output gap misperceptions under the optimal policy in the New-Keynesian model is shown in Figure $\mathbf{1}$ for a single draw of normallydistributed cost-push, demand and money-demand shocks and noise terms. Due to an 
Figure 1: Output Gap Misperceptions and the Money-Inflation Link
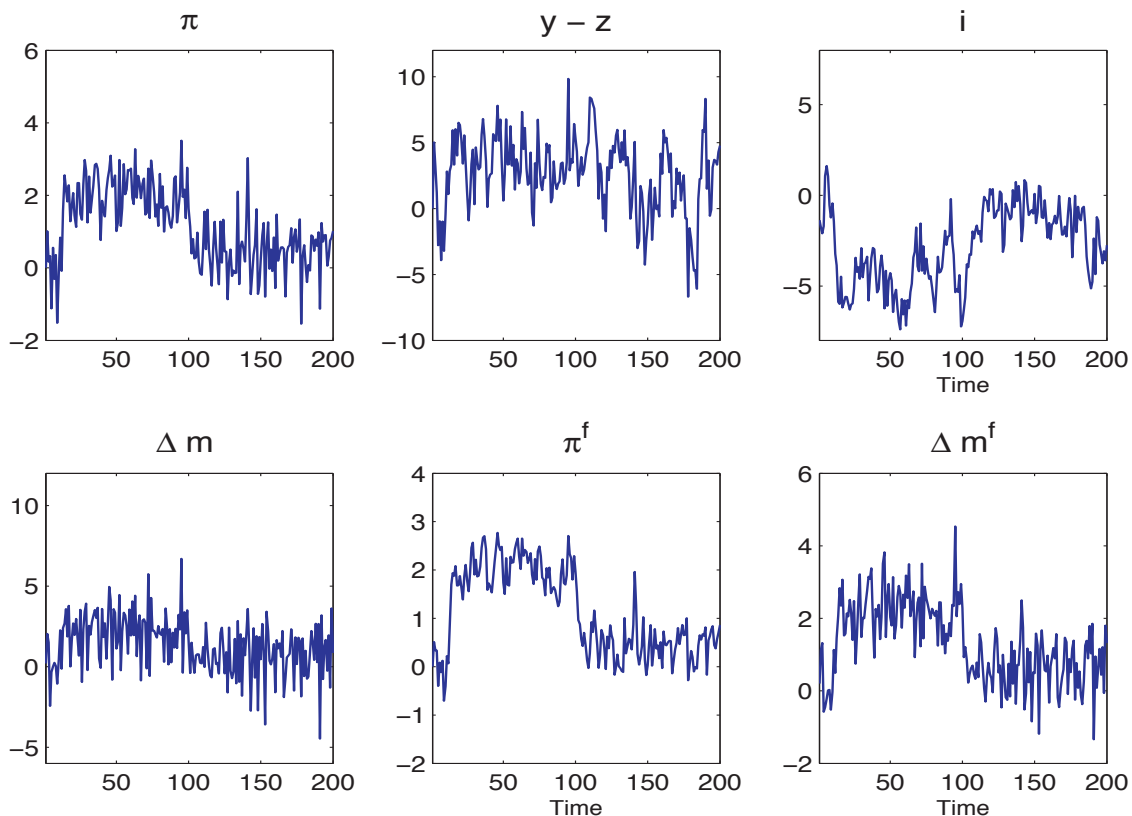

interest rate policy that is more accommodative than the central bank believes to be the case, money growth and inflation rise. This increase is persistent due to persistent central bank misperceptions regarding potential output. Over time, also the filtered measures of money growth, $\Delta m^{f}$, and inflation, $\pi^{f}$, increase. An apparent trend change in nominal variables occurs.

The simulation reported in Figure 1 suggests that the introduction of imperfect knowledge and persistent central bank misperceptions is sufficient to provide a unified account of monetary and inflation trends - the unresolved issue on the frontier of macroeconomic theory noted by Robert E. Lucas. Of course, the series of misperceptions simulated above is an ad-hoc choice. However, empirical observations of central bank misperceptions are available for the United States and Germany from Orphanides (2003) and Gerberding et al. (2006). Beck and Wieland (2008) show that these historical misperceptions also generate similar trends in money growth and inflation.

Another potential source of inflation trends that has been considered in empirical estimations of the New-Keynesian model is the inflation target. A common assumption is to model the central bank's inflation target as a random walk. Our explanation based on persistent policy mistakes due to persistent misperceptions regarding unobservables applies in the case of a constant inflation target. It makes use of the empirical observation of persistent output gap revisions and does not require random changes in the central bank's inflation objective.

With regard to the simulation in Figure 1 one may ask why the central bank does not realize that its perceptions are biased, raises interest rates to a higher level and thereby 
ensures that inflation returns to target relatively quickly. The reason is simple. Optimal monetary policy takes account of the best available forecast for inflation. This forecast, which is based on an incorrect output gap, states that inflation will return to target due to the belief that aggregate demand is consistent with price stability. If the central bank were to raise interest rates further, its own forecast would indicate a recession and undershooting of its inflation target. The persistent bias in the forecast implies that the central bank is attributing successive periods of high inflation to a sequence of unfavorable shocks rather than a mistaken output gap estimate. This example is not without parallel in reality considering the account of the 1970s inflation in the United States in Orphanides (2003).

\section{An interest rate policy with monetary cross-checking}

Based on the empirical evidence on money growth and inflation trends, Lucas (2007) suggested to continue using information on monetary aggregates as an add-on or crosscheck in interest rate policy. In this spirit, we have formulated an interest rate rule with monetary cross-checking in Beck and Wieland (2007a). It consists of two components:

$$
i_{t}=i_{t}^{N K}+i_{t}^{C C}
$$

The first component, denoted by the superscript $N K$, refers to the optimal interest rate policy in the New-Keynesian model as defined by equation (19) in section 2 . The second component, denoted by the superscript $C C$, refers to an additive adjustment in interest rate setting due to monetary cross-checking.

What is the purpose of having two components? If the central bank believes in the New-Keynesian model, the available information and estimates indicate that $i_{t}^{N K}$ is the optimal policy choice under uncertainty. In the case of persistent output gap misperceptions, the model-based forecast will indicate that a sequence of inflationary shocks is the source of the observed upward shift in inflation rather than a deviation of output from potential. It is important to understand that this assessment also incorporates information on monetary aggregates. The New-Keynesian model will attribute the upward shift in money growth to the same source. Money is not a neglected information variable. Conditional on the model and the model-consistent output gap estimate money growth does not provide further information affecting the model forecast. The reason is that the level of output and inflation are observed directly. If output, inflation and money growth were afflicted with measurement error, money would provide further information that would help improve estimates of current output and inflation. This information role is investigated by Coenen et al. (2005), but plays no role in the present paper.

Instead, the idea of cross-checking is motivated from the perspective of model un- 
certainty and the search for robustness in policy design. The proposal is to base policy on the preferred model in normal times, but to check policy outcomes regularly against another simpler model. In this paper, the preferred model is the New-Keynesian model of section 2. The simpler model used for cross-checking is the long-run relationship between money and inflation implied by the quantity theory. Of course, as shown in the preceding section, this long-run relationship between money and inflation is part of the New-Keynesian model as well. It is interesting from a robustness perspective, because it also holds in cases where the New-Keynesian model fails, for example, in an economy that is better characterized by a model without price rigidities. Ideally, the regular crosscheck should not lead to deviation from the New-Keynesian interest rate policy, $i_{t}^{N K}$, in normal times, that is in the absence of persistent central bank misperceptions regarding unobservable measures such as the output gap. However, the cross-check should trigger a policy adjustment, $i_{t}^{C C}$, if trend money growth deviates from a rate consistent with stable inflation in a statistically unusually persistent manner. This statistical test may be based on the null hypothesis that the preferred model is correct.

As shown by Beck and Wieland (2008) the policy with cross-checking can be derived from a first-order condition that includes trend inflation. To illustrate the reasoning we start by reiterating the first-order condition that describes the optimal policy derived under certainty-equivalence:

$$
E\left[\pi_{t+i}-\pi^{*} \mid t\right]=0 \quad \forall i=\{0,1,2, . ., \infty\}
$$

It implies that trend inflation equals the inflation target in expectation. Specifically, $E\left[\pi_{t+N} \mid t\right] \rightarrow E[\bar{\pi}]$ as $N \rightarrow \infty$, and consequently $E[\bar{\pi}]=\pi^{*}=0$.

Thus, a central bank that relies on the New-Keynesian model expects that trend inflation will turn out to match the target as long as policy is set to stabilize expected inflation in every period. However, such confidence in model-based forecasts and estimates of unobservable variables may be misplaced. Following Lucas' recommendation, a sceptical policy maker may instead consider a simpler model of trend inflation. A good candidate is the long-run relationship between money and inflation derived from the quantity equation:

$$
E[\bar{\pi}]=E\left[\mu^{f}\right]
$$

A "monetarist" central bank that exclusively uses this model of trend inflation to inform policy would conduct open-market operations in period $t$ such that trend inflation as estimated by the most recent observation on filtered adjusted money growth is expected to equal the inflation target:

$$
E\left[\bar{\pi} \mid \mu_{t}^{f}\right]=\pi^{*}=0 .
$$

$\mu_{t}^{f}$ can be monitored without relying on model-based estimates of potential output. As 
a result, the central bank can stabilize trend inflation in spite of output gap misperceptions. $^{9}$

Clearly, such an approach may appeal to traditional strict monetarists. In our view, however, it would be a mistake to abandon any attempt at short-run inflation stabilization. After all, the New-Keynesian model may not be that far off the mark and potential output estimates need not always be utterly wrong. Instead, we consider the monetary model of trend inflation for cross-checking purposes. Specifically, the central bank is instructed to check every period whether filtered money growth is still consistent with attaining the inflation target or whether trend money growth has shifted. This check is accomplished by monitoring the test statistic,

$$
\kappa_{t}=\frac{\mu_{t}^{f}-\pi^{*}}{\sigma_{\mu^{f}}},
$$

and comparing it to a critical value $\kappa^{\text {crit }}$. Here, $\sigma_{\mu^{f}}$ denotes the standard deviation of the filtered money growth measure. It can be determined under the null hypothesis that the central bank's preferred model, that is the New-Keynesian model is correct.

As long as the test statistic does not signal a sustained shift in filtered money growth, the central bank implements the optimal policy under the preferred Keynesian-style model. This is the policy that satisfies the first-order condition (7). As a result it will stabilize short-run inflation variations very effectively in the absence of persistent output gap misperceptions. Once the central bank receives successive signals of a shift in trend inflation as estimated by filtered money growth, i.e. $\left(\kappa_{t}>\kappa^{\text {crit }}\right.$ for $N$ periods $)$ or $\left(\kappa_{t}<-\kappa^{\text {crit }}\right.$ for $N$ periods), policy is adjusted so as to control trend inflation.

The two policy parameters $\kappa^{c r i t}$ and $N$ play different roles. $\kappa^{\text {crit }}$ reflects the probability that an observed deviation of $\mu^{f}$ from $\pi^{\star}$ is purely accidental (for example a $5 \%$ or $1 \%$ significance level). $N$ defines the number of successive deviations in excess of this critical value. Thus, the greater $N$ the longer the central bank waits to accumulate evidence of a sustained policy bias. The chosen values are shown in Table 2.

Table 2: Parameters of the Cross-Checking Component of Monetary Policy

\begin{tabular}{lll}
\hline \hline Parameter & Value & Economic interpretation \\
\hline$\sigma_{\mu^{f}}$ & 0.54 & $\begin{array}{l}\text { Standard deviation of } \mu^{f} \text { given the calibration of the } \\
\text { model equations in Table } 1 .\end{array}$ \\
$\kappa^{\text {crit }}$ & 1.96 & $\begin{array}{l}5 \% \text { critical value for the cross-checking rule. } \\
N\end{array}$ \\
4 & $\begin{array}{l}\text { Number of periods required for a sustained deviation in } \\
\text { the cross-checking rule. }\end{array}$ \\
\hline \hline
\end{tabular}

The optimal size of the cross-checking adjustment can be derived from a first-order

\footnotetext{
${ }^{9}$ Of course, a natural question concerns the implications of sustained velocity shifts for this strategy of stabilizing trend inflation. This possibility is investigated in Beck and Wieland (2008). There we show that simple recursive estimation of money demand parameters would be effective in avoiding incorrect cross-checks.
} 
condition that includes the expectation of trend inflation based on the simple monetary model. It is used to augment the inflation forecast based on the New-Keynesian (NK) model:

$$
E\left[\pi_{t} \mid z_{t \mid t}^{e}, \text { NK Model }\right]+E\left[\bar{\pi} \mid \mu_{k}^{f}\right]=0
$$

This condition guarantees that the central bank counteracts a significant shift in trend inflation estimated on the basis of filtered money growth. $\mu_{k}^{f}$ denotes the most recent significant estimate of a trend shift in period $k$, i.e. $\left(\kappa_{k}>\kappa^{\text {crit }}, . ., \kappa_{k-N}>\kappa^{\text {crit }}\right)$ or $\left(\kappa_{k}<\right.$ $\left.-\kappa^{\text {crit }}, . ., \kappa_{k-N}<-\kappa^{\text {crit }}\right)$.

To derive the interest rate adjustment following a significant cross-check it is important to consider its effect on market participants' expectations of future inflation. Of course, initially neither the central bank nor market participants will expect crosschecking to kick in, because expectations are formed conditional on the New-Keynesian model and the associated estimate of potential output. The probability that the test statistic $\kappa$ exceeds the critical value under the null hypothesis is negligible, and even more so the probability that it exceeds $\kappa^{c r i t}$ for $N$ periods. Thus, in the absence of a significant cross-check the expectations for inflation in period $t$ under the null hypothesis of the New-Keynesian model and the potential output estimate $z_{t \mid t}^{e}$ are given by

$$
\pi_{t \mid t}^{e}=0
$$

Once a significant cross-check occurs, policy is governed by the first-order condition with the monetary estimate of trend inflation from then onwards. As a consequence:

$$
\pi_{t \mid t}^{e}=-\mu_{k}^{f}
$$

Thus, under symmetric information the central bank and market participants will expect current inflation - conditional on the New-Keynesian model and potential output estimate - to fall below the target to the extent of the trend inflation estimate provided by filtered money growth.

To solve the New-Keynesian Phillips curve for the expected output level that the central bank should aim at according to the policy with cross-checking, it is necessary to characterize market participants' expectation of inflation in period $t+1$. In doing so we focus on the case of policy under discretion. In this case, the central bank cannot manipulate market participants' inflation expectations by promising to commit to delivering future inflation outcomes that are inconsistent with its objective function. Therefore, under discretion market participants expect future inflation to return to the zero inflation target of the central bank, i.e. $\pi_{t+1 \mid t}^{e}=0$.

Then, the Phillips curve is solved for the level of output that the central bank expects 
to achieve in period $t, y_{t \mid t}^{e}$. Using $\pi_{t+1 \mid t}^{e}=0$ and $\pi_{t \mid t}^{e}=-\mu_{f}^{k}$ one obtains

$$
\begin{aligned}
y_{t \mid t}^{e} & =z_{t \mid t}^{e}+\frac{1}{\lambda} \pi_{t \mid t}^{e}-\frac{\beta}{\lambda} \pi_{t+1 \mid t}^{e}-\frac{1}{\lambda} u_{t \mid t}^{e} \\
& =z_{t \mid t}^{e}-\frac{1}{\lambda} u_{t \mid t}^{e}-\frac{1}{\lambda} \mu_{f}^{k} .
\end{aligned}
$$

Market participants' expectation of output in period $t+1$ may be characterized in a similar manner. Consistent with the expectation that inflation will be equal to the target in period $t+1$, market participants expect output to be equal to potential output in period $t+1$ :

$$
y_{t+1 \mid t}^{e}=z_{t+1 \mid t}^{e}-\frac{\rho_{u}}{\lambda} u_{t \mid t}^{e} .
$$

In the next step, the IS curve is solved for the interest rate, $i_{t}$, consistent with the above expressions for $y_{t \mid t}^{e}, y_{t+1 \mid t}^{e}$ and $\pi_{t+1 \mid t}^{e}$. This yields the interest rate policy with crosschecking:

$$
\begin{aligned}
i_{t} & =0-\frac{1}{\varphi}\left(z_{t \mid t}^{e}-\frac{1}{\lambda} u_{t \mid t}^{e}-\frac{1}{\lambda} \mu_{f}^{k}\right)+\frac{1}{\varphi}\left(z_{t+1 \mid t}^{e}-\frac{\rho_{u}}{\lambda} u_{t \mid t}^{e}\right)+\frac{1}{\varphi} g_{t \mid t}^{e} \\
& =\frac{1}{\varphi}\left(z_{t+1 \mid t}^{e}-z_{t \mid t}^{e}+\frac{1-\rho_{u}}{\lambda} u_{t \mid t}^{e}+g_{t \mid t}^{e}\right)+\frac{1}{\lambda \varphi} \mu_{f}^{k} \\
& =i_{t}^{N K}+\frac{1}{\lambda \varphi} \mu_{f}^{k} .
\end{aligned}
$$

It turns out that the appropriate adjustment to interest rate policy for the periods following a significant cross-check is given by $i_{t}^{C C}=\frac{1}{\lambda \varphi} \mu_{f}^{k}$. The dynamic characterization of interest rate policy then corresponds to:

$$
i_{t}= \begin{cases}i_{t}^{N K}+\left(\frac{1}{\varphi \lambda}\right)\left(\mu_{k}^{f}\right) & \text { if }\left(\kappa_{t}>\kappa^{c r i t}, . ., \kappa_{t-N}>\kappa^{c r i t}\right) \\ & \text { or } \left.\left(\kappa_{t}<-\kappa^{c r i t}, . ., \kappa_{t-N}<-\kappa^{c r i t}\right)\right) \\ i_{t}^{N K}+0 & \text { else. }\end{cases}
$$

Next, we aim to show that the interest rate policy with cross-checking provides a convenient and effective avenue for correcting the central bank's policy bias that lead to the sustained increase in filtered money growth and inflation in the preceding simulation. To this end, we repeat the simulation of Figure 1 using the policy defined by equation (40). The outcome is reported in Figure 2. The panel with actual money growth, $\Delta m$, is omitted. Instead we include a panel reporting the misperception in the central bank's estimate of potential output, $e_{t}$, and the adjustment in interest rates due to monetary cross-checking, $i_{t}^{C C}$.

The policy with cross-checking responds to the increase in filtered money growth, $\mu_{t}^{f}$, fairly quickly after the policy bias has arisen. The interest rate adjustment of $\left(\frac{1}{\lambda \varphi}\right)\left(\mu_{k}^{f}\right)$ almost perfectly offsets the policy bias due to the output gap misperception, $\left(e_{t}\right)$. Once 
Figure 2: Output Gap Misperceptions and Monetary Cross-Checking
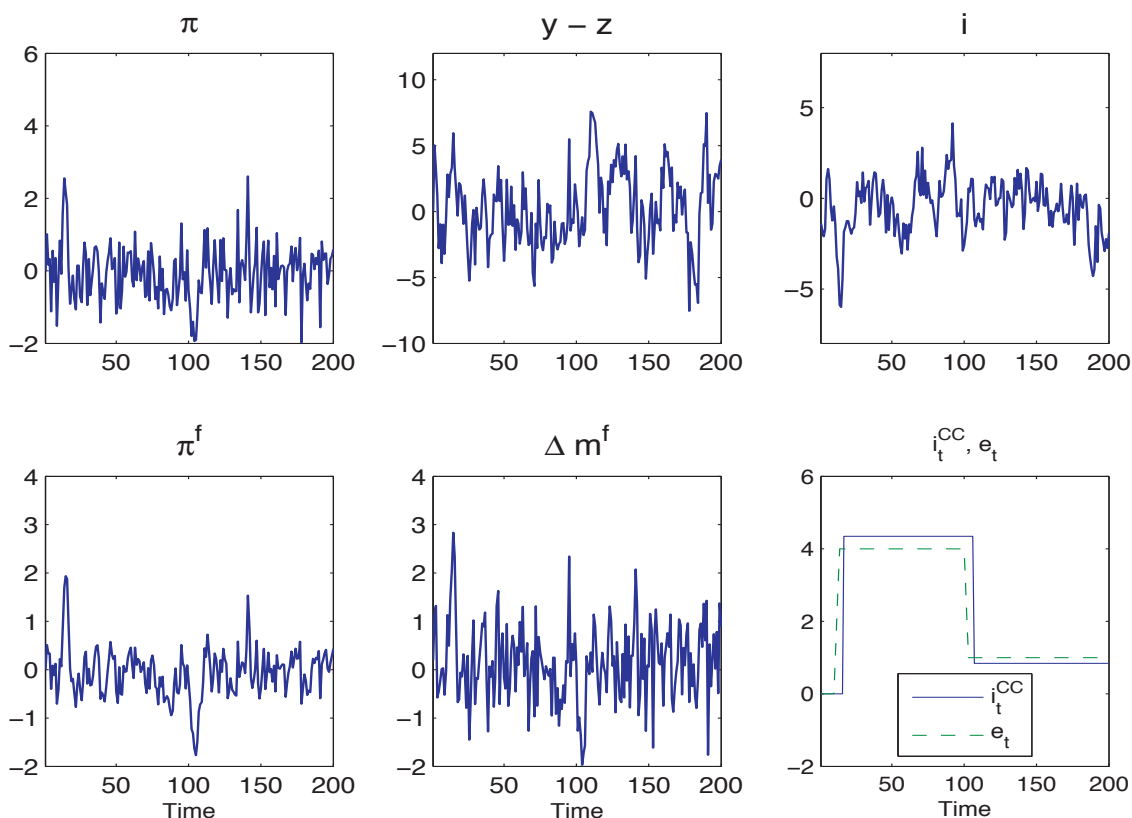

the misperception of potential output declines after period 100 cross-checking soon leads to another adjustment of interest rates.

To assess the sensitivity of our findings we draw 1000 series of shocks of 200 periods length from a normal distribution and use them to conduct a set of alternative simulations. Some of the findings are reported in Figure 3. The bottom right panel of Figure 3 reports the average path of the interest rate adjustment due to monetary cross-checking, i.e. $i_{t}^{C C}$, over 1000 simulations under the same parameter settings as in the single simulation displayed in Figure 2. This panel confirms that, on average, cross-checking leads to the appropriate interest rate adjustments offsetting the policy bias due to output gap misperceptions. 
Figure 3: Sensitivity Analysis: Averages over 1000 Simulations
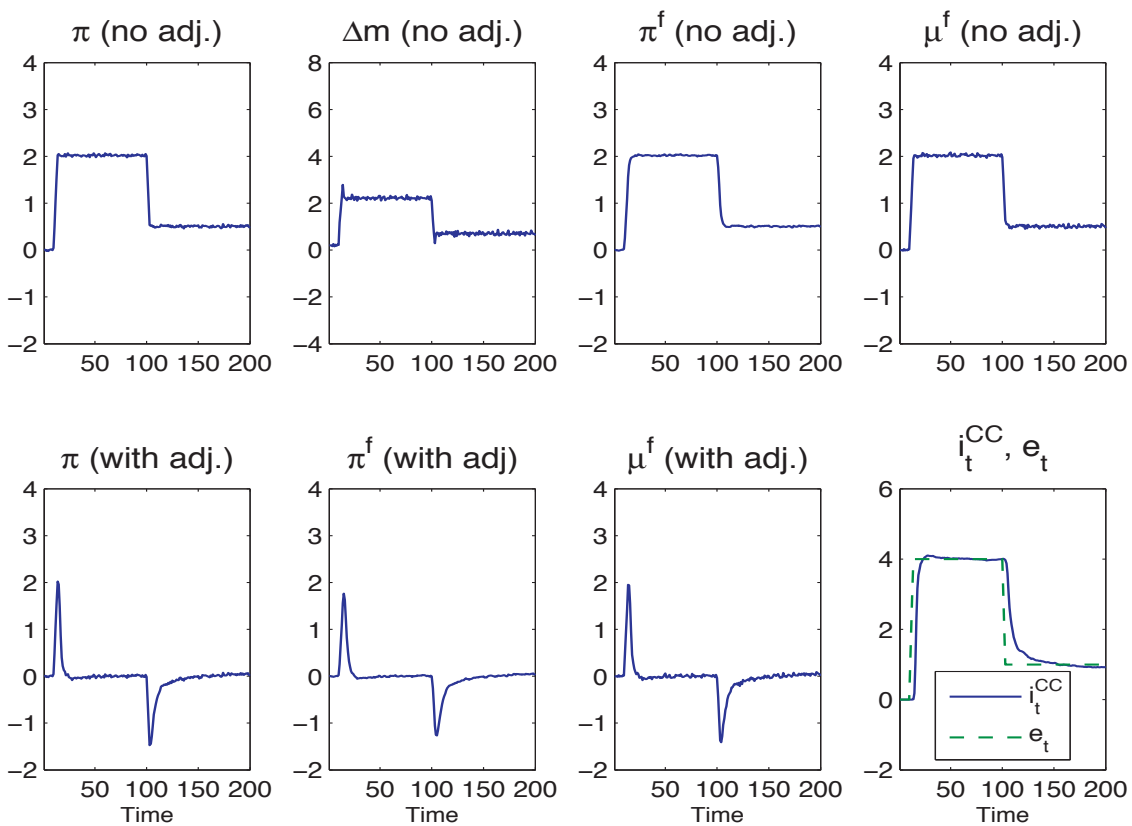

\section{Conclusions and Outlook}

In this paper, we have presented the case for monetary policy without money in the NewKeynesian model. This analysis supports Michael Woodford's conclusion that monetary aggregates do not play an important role in optimal interest rate policy. Furthermore, we have shown that the empirical observation of similar trends in money growth and inflation is not in itself a reason to discard the New-Keynesian model. Similar long-run trends of money growth and inflation can be explained within the New-Keynesian model. Our analysis indicates that such trends would emerge as a consequence of a sustained policy bias. A possible source of this bias are persistent central bank misperceptions regarding unobservable potential output. Empirical evidence on the existence of such misperceptions is available for the United States and Germany.

Nevertheless, we find that monetary aggregates can play a useful role in designing a robust monetary policy strategy. In particular, it may be useful to augment the optimal model-based interest rate policy with a monetary cross-check if the central bank's modelbased estimates of unobservables such as potential output embody persistent misperceptions. Such a cross-check can help correcting the policy bias due to misperceptions by adding an adjustment to the interest rate prescription from the central bank's preferred New-Keynesian model that is derived from a money-based estimate of trend inflation. This adjustment would not be made in normal times, but only when the money-based estimate of trend inflation has deviated in an unusual and persistent manner from tar- 
get. The optimal interest policy prescription from the preferred New-Keynesian model does not adjust automatically, because the central bank's output gap estimate and modelbased forecast interpret the change in inflation simply as the outcome of a particularly unfavorable series of shocks.

In Beck and Wieland (2007a,b) we have noted the similarity between monetary cross-checking as defined above and the ECB's claim that it bases its interest-rate decisions on a strategy with two main components or pillars. In particular, the ECB's strategy is not exclusively focused on short- to medium-run determinants of inflation, but also includes a separate, long-run oriented monetary analysis. The ECB website describes these two components as follows:

"Economic analysis assesses the short to medium-term determinants of price developments. The focus is on real activity and financial conditions in the economy. The economic analysis takes account of the fact that price developments over those horizons are influenced largely by the interplay of supply and demand in the goods, services and factor markets."

"Monetary analysis focuses on a longer-term horizon than the economic analysis. It exploits the long-run link between money and prices. The monetary analysis mainly serves as a means of cross-checking, from a medium to long-term perspective, the short to medium-term indications for monetary policy coming from the economic analysis."

We are tempted to associate the ECB's "economic analysis" with the optimal interest rate policy derived from the New-Keynesian model, denoted by $i_{t}^{N K}$ in this paper. Our reasoning for this association is that this setting of the interest rate will ensure that shortto medium-run inflationary risks based on a forward-looking Phillips curve and excess aggregate demand are perfectly controlled. Similarly, we are tempted to associate the ECB's "monetary analysis" with the cross-checking adjustment, denoted by $i_{t}^{C C}$. As outlined in the preceding section this adjustment exploits the long-run link between money and prices. However, we note that the ECB has refrained from providing a formal quantitative exposition of the conduct and combination of its "economic" and "monetary" analysis. Therefore, this association remains speculative and in need of further empirical investigation.

Our definition of a policy with cross-checking would also allow incorporating crosschecks regarding other estimates of trend inflation. While the quantity theory suggests filtered money growth as an obvious candidate, past measures of filtered inflation would work as well (see Beck and Wieland (2008)). However, those staff in charge of inflation forecasting may be reluctant to insist on an additional policy response to past inflation that would lead them to predict an under- or over-shooting of inflation conditional on the preferred model of inflation. For this reason, one could also speculate whether such 
an insistence on reacting to past outcomes is perhaps better incorporated in the context of a long-run monetary analysis conducted separately from those in charge of short-run inflation forecasting in a central bank.

\section{References}

Andres, J., Lopez-Salido, J. D., and Valles, J. (2006). Money in an estimated business cycle model of the euro area. Economic Journal, 116:457-477.

Assenmacher-Wesche, K. and Gerlach, S. (2007). Interpreting euro area inflation at high and low frequencies. Journal of the European Economic Assocation, 5:534-542.

Beck, G. W. and Wieland, V. (2002). Learning and control in a changing economic environment. Journal of Economic Dynamics and Control, 26(9-10):1359-1377.

Beck, G. W. and Wieland, V. (2007a). Money in monetary policy design: A formal characterization of ECB-style cross-checking. Journal of the European Economic Association, 5:524-533.

Beck, G. W. and Wieland, V. (2007b). Money in monetary policy design: The two-pillar phillips curve versus ECB-style cross-checking. CEPR Discussion Paper, No. 6098.

Beck, G. W. and Wieland, V. (2008). Central bank misperceptions and the role of money in interest rate rules. Journal of Monetary Economics, 55S:S1-S18.

Benati, L. (2005). Long-run evidence on money growth and inflation. Bank of England Quarterly Bulletin.

Bils, M. and Klenow, P. (2004). Some evidence on the importance of sticky prices. Journal of Political Economy, 112:987-985.

Christiano, L. J. and Rostagno, M. (2001). Money growth monitoring and the Taylor rule. NBER Working Paper No. 8539.

Clarida, R., Gali, J., and Gertler, M. (1999). The science of monetary policy: A new Keynesian perspective. Journal of Economic Literature, XXXVII:1661-1701.

Coenen, G., Levin, A. T., and Wieland, V. (2005). Data uncertainty and the role of money as an information variable for monetary policy. European Economic Review, 49:975-1006.

Gerberding, C., Seitz, F., and Worms, A. (2006). Monetary policy and real-time data: The case of Europe, Asia and the US. In Welfens, P., Knipping, F., Chirathivat, S., and Ryan, C., editors, Integration in Asia and Europe: Historical Dynamics, Political Issues, and Economic Perspectives, pages 165-182. Springer. 
Gerlach, S. (2004). The two pillars of the European Central Bank. Economic Policy, 40:389-439.

Goodfriend, M. and King, R. G. (1997). The new neoclassical synthesis and the role of monetary policy. In Bernanke, B. S. and Rotemberg, J. J., editors, National Bureau of Economic Research Macroeconomics Annual 1997. MIT Press, Cambridge, MA.

Ireland, P. N. (2004). Money's role in the monetary business cycle. Journal of Money, Credit and Banking, 36:969-983.

Kerr, W. and King, R. G. (1996). Limits on interest rate rules in the is model. Economic Quarterly, (Spr):47-75.

Lucas, Jr., R. E. (2007). Central banking: Is science replacing art? in Monetary Policy: A Journey From Theory to Practice, European Central Bank.

Orphanides, A. (2003). The quest for prosperity without inflation. Journal of Monetary Economics, 50:633-663.

Orphanides, A., Porter, R. D., Reifschneider, D., Tetlow, R. J., and Finan, F. (2000). Errors in the measurement of the output gap and the design of monetary policy. Journal of Economics and Business, 52:117-141.

Pill, H. and Rautananen, T. (2006). Monetary analysis - the ECB experience. Paper presented at the conference "The ECB and its Watchers VIII", May 5, 2006.

Rotemberg, J. J. and Woodford, M. (1997). An optimization-based econometric framework for the evaluation of monetary policy. in B. Bernanke and J. Rotemberg, (eds.), NBER Macroeconomics Annual, The MIT Press.

Svensson, L. E. O. (1997). Inflation forecast targeting: Implementing and monitoring inflation targets. European Economic Review, 41:1111-1146.

Svensson, L. E. O. and Woodford, M. (2003). Indicator variables for optimal policy. Journal of Monetary Economics, 50:691-720.

Wieland, V. (2000). Learning by doing and the value of optimal experimentation. Journal of Economic Dynamics and Control, pages 1-29.

Wieland, V. (2006). Monetary policy and uncertainty about the natural unemployment rate: Brainard-style conservatism versus experimental action. Advances in Macroeconomics, 6(1).

Woodford, M. (2003). Interest and prices: Foundations of a theory of monetary policy. Princeton University Press, Princeton. 
Woodford, M. (2006). How important is money in the conduct of monetary policy? paper prepared for the Fourth ECB Central Banking Conference, The Role of Money: Money and Monetary Policy in the Twenty-First Century. 
